\title{
Spot Natural Gas Prices: A Theoretical Party to \\ Party Bargaining Framework
}

\author{
John Simpson \\ Curtin University \\ Perth Western Australia, G P O Box U1987, Perth \\ Australia 6001 \\ Tel: 8-9266-4417Ｅ-mail: simpsonj@cbs.curtin.edu.au
}

\begin{abstract}
Whilst some regional energy markets appear to be integrating, modelling the pricing of natural gas exports in an imperfect global spot market remains a difficult task. For the sake of analysis, this paper proposes the expansion of a theoretical global party to party spot gas price bargaining model to capture lagged daily prices of the major competing fuels and values of a global economic indicator in the world stock market price index. Vector autoregressive based tests provide no evidence of cointegration, however tests of exogeneity show that gas prices and gas price changes are primarily influenced by oil prices and oil price changes. Within this framework, it is found that the oil price and oil price changes are influenced significantly by global stock price index values and index value changes and the coal price index values and index value changes. The model put forward is purely for preliminary analysis but it shows potential. All markets need to become larger, more globally integrated, more informationally efficient and mechanisms to arbitrage the various energy markets would need to be established before a final global gas spot price index is possible.
\end{abstract}

Keywords: Gas pricing, Stock prices, Oil prices, Economic expectations, Benchmark, $\mathrm{HH}$

\section{Introduction}

Cartel pricing for gas, as suggested by some that support the OPEC oil pricing model, is generally rejected by free market economists. Based on studies of cartel versus competitive behaviour, collusive pricing behaviour is rejected in this paper. Economic theory and fact says that cartel behaviour is monopoly pricing. Cartel behaviour is not consistent with market efficiency. It interferes with supply by imposing production limits. It distorts prices. In the late 1970s the OPEC cartel has been blamed for price hikes that caused the energy crisis of the 1980s and subsequent global financial instability (For example, the Latin American debt crises of the late 1980s early 1990s). A global benchmark price for gas determined by world supply and demand is ultimately desirable, as it will, as in any other market; result in the most efficient allocation of scarce and depletable resources.

An increasing number of countries are concerned with energy costs and environmental issues surrounding nuclear, coal and oil power generation for industry and households. Domestic and foreign direct investment has mobilised funds for gas as an alternative energy source with funds applied to exploration and infrastructure for transport, liquefaction, storage and power generation. However, despite the lack of a global integrated market, pricing of natural gas in some domestic and regional markets is making progress towards efficiency. There is a greater choice of natural gas contracts through deregulation and restructuring in many countries. For example, in the USA since 1984 there has been a separation of natural gas supply from interstate pipeline transportation, deregulated natural gas production and the wholesale market, and competition has been introduced in interstate pipeline transportation. In 1986 the British government privatised British Gas. In 1992, Argentina separated and then privatised natural gas production, transportation and distribution. Mexico opened up its market to competition in 1993. Hungary separated and privatised distribution companies in 1994-95. Privatisation is increasingly being seen as a means of improving efficiency and increasing investment. On the global supply side, gas reserves are substantial for the time being and are often found along-side oil reserves in many countries. For example, Australia has enormous reserves from the oil producing area North West Shelf. It will compete strongly with Middle Eastern and other suppliers over the next decade. 
Whilst contract formulae or specific contract prices are not in general for public knowledge, LNG pricing for importing countries is receiving greater attention as more countries move over to gas energy. The method of import pricing of LNG is known to differ from region to region. The pricing is usually linked to oil prices but which oil prices are they linked to? In Asia (For example Japan) the import price formula is based on a basket of crude oil prices commonly referred to as the Japanese Crude Cocktail (JCC).

However, this is not the case in China, which has provided for lower prices and weaker linkages to oil prices. It may be that the Chinese rely on high volumes in large contracts to entice exporters such as Australia into lower prices despite global conditions of excess demand (For example, the first Chinese project in Guangdong, negotiated in 2002 with the first delivery June 2006). Of course the Chinese regard this price as a precedent price and will always negotiate towards this lower bound. (Note 1) Australian exporters will, however, negotiate in future towards the upper bound which could be in excess of, for example, the bound negotiated by Japanese importers. Figure 1 is cited in Eng (2006) and shows the differences in the Japanese and Chinese pricing models for LNG gas imports.

European gas prices are linked to Brent oil prices. In Europe gas imports compete with pipeline imports and indigenous supplies of gas in many European countries. The USA market is re-emerging as indigenous supplies and Canadian imports are depleted and LNG imports grow. The USA gas market is the most dynamic of all regional markets. Imports are growing and are sourced through both spot and short-term contracts.

Eng (2006) builds a case for the adoption by New Zealand of a lower bound Chinese pricing model for LNG imports. These imports may not necessarily be sourced from Australia but the distance from Australia to New Zealand compares to that from Australia to China. Whilst the case for the Chinese model is compelling for New Zealand, it is not for Australia, as the volumes required would be expected to be substantially less and Australia has already negotiated closer to the upper Japanese pricing bound with other countries. (Note 2) It is clear that a pricing formula for both forecasting and negotiation of global gas prices is needed. Whether or not such a formula is currently practical in such an inefficient energy market is another question. At least a spot pricing model can and should be put forward for preliminary analysis.

\section{Market Background}

Whilst the regional natural gas markets are becoming more deregulated, integrated and efficient, excess demand in the global market is forcing up both spot and contract prices. Supply is unable to adjust to demand because of delays in infrastructure completion for pipelines, port facilities, liquefaction plants and shipping. The spot market is believed to account for between $10 \%$ and $20 \%$ of the total gas market. Most gas is sold on long-term fixed price contracts. Brito and Hartley (2007) have noted recent changes in the liquefied natural gas market where shorter term multinational trades are being favoured relative to long-term bilateral and project specific contracts. Brito and Hartley find that just as oil markets had changed, changes to the gas market structure in short-term trades could occur quite rapidly. A global spot benchmark price for natural gas is becoming more important as a basis for exporter and importer price negotiations. Such a benchmark will also be useful in forecasting and to manage price risk in long-term contracts for both buyers and sellers. Deregulation in the natural gas industry has produced two types of market. The first is a production market where gas is traded as a commodity. This includes the export market for liquefied natural gas (LNG). There is also a market where participants can trade the shipment of gas through conventional sea shipping and through pipeline systems. Both involve substantial transportation costs. The socially optimal outcome in a country or region is where there is a simultaneous clearing of natural gas production and transportation markets. To achieve this, two models have been developed and discussed by Juris (2005). The easy to implement and popular "bilateral trading" model relies on decentralised bilateral negotiations. The "poolco" model has great potential and relies on a centralised entity that coordinates individual transactions. The drawback of the latter model lies in problems of sharing and processing of information. In order to simplify the analysis this paper develops an expanded global party to party bargaining model.

It is useful to first look at constraints for natural gas as an energy alternative. According to Okogu (2002), there are several factors that restrict the development of natural gas as an energy source. Impediments are the opaqueness of gas contracting processes and the absence of a global market. Okogu (2002) thinks that foreign direct investment might monetise some of the stranded reserves but, the success of that depends on investor friendly climates. These include more liberal tariff regimes in domestic markets. It is clear that political risk factors act to inhibit necessary investment in natural gas infrastructures to free up supply bottlenecks. This is the subject of future research as it is evident that political risk factors will also affect pricing.

The USA and Europe are important potential markets for Australian LNG. The USA market players, concerned with depletion of resources at home and in Canada, continue to examine alternatives for diversification of suppliers. There is also concern about supply continuity as the pace of industrial usage of gas increases. There remains a debate in Australia as to whether or not prices negotiated for large export contracts in the past were below the market price. Perhaps this was due to the fact that a satisfactory benchmark price was not available or had not been properly considered. 
It is expected that the global gas market will become increasingly liquid. Exporting countries are endeavouring to diversify their buyers. Importing countries are trying to diversify their sources. Producing countries have enormous reserves that need to be brought to the production stage. Consumer countries are investing heavily in port, liquefaction, storage and pipeline infrastructures. Japan is investing in increasing its LNG marine shipment capability.

However, at the time of writing, conditions of excess demand exist. Importers are unable to purchase gas in a global market that has been unable to keep up with production and transport infrastructure. Even in the spot market ships are being re-routed according to prices offered by buyers when the ships have left port. This situation will change as supply infrastructure catches up over the next decade. The global market players are striving to match supply with demand.

Given these market conditions, the purpose of this paper is to examine the feasibility of an interim spot benchmark pricing model for natural gas, taking into account a variable that partially reflects supply and demand forces and variables that represent replacement energy sources in an expanded party to party bargaining model. If an acceptable and available series of spot gas prices can be significantly explained by these variables, an interim benchmark gas pricing model will be provided to assist in party to party spot or contract price negotiations. Such a model will also serve as a partial gas price forecaster.

\section{Theory and literature}

In international trade in commodities, an international spot price reference point inevitably evolves. For example, West Texas Intermediate is the reference point for sweet crude oil traded in the Atlantic basin. Brent Oil is the benchmark in Europe. The National Balancing Point (NBP) is the gas price benchmark in the UK. To commence an analysis of what the benchmark should be it necessary to differentiate the natural gas industry in areas of production, pipeline transportation, shipping transportation, trading and supply, and distribution.

There are of course different costs associated with these areas in different economies with different levels of economic development (and different levels of political risk). The costs of factors of production differ from country to country. Nevertheless, in a global market place, a basic export price is needed as a benchmark. This basic indicator price will be adjusted upwards according to differing costs of transportation, trading and supply infrastructures, and infrastructures relating to distribution in bilateral trading relationships.

\subsection{Prices and market forces}

According to theory and the Law of One Price as revisited by Asche, (2000), in an integrated market, prices on homogenous goods from different producers and suppliers should move together. Price differentials should only indicate differences in transportation costs and quality. In forming a benchmark spot export price as a basis for negotiation, the focus should be on a standard quantity and quality of natural gas on a free on board (fob) basis from the terminal. This paper posits that it is more important that a spot fob benchmark price be established for ex-terminal gas irrespective of whether it is loaded into a pipeline or onto a ship in the form of LNG.

Consistent with this theoretical base, a global spot benchmark for gas should be based on the costs involved in the natural gas production segment and on the operations necessary to deliver the gas from the wellhead to the terminal in the exporting/producing country. The benchmark would exclude the sunk costs of exploration and drilling. It would also exclude the international shipment transportation costs, but include the average costs in each export/producing market (weighted by volumes exported) in production and gathering at the wellhead, and only transportation costs to the terminal in the exporting country.

The benchmark price should also include the costs of standardising quality at the terminal in the exporting/producing country. This would represent a fair fob export benchmark price and differing costs of these operations would be reflected in a unit of currency (for example, the US dollar or the Euro) in different exporting/producing countries. Exporter/producers and importer/consumers would need to place credibility in a formula for a benchmark as an indicator only for the global market price. It may be necessary for a neutral central authority to collect data, to quote prices daily and to supervise standardisation.

The benchmark would be a minimum price. Individual transaction prices would need to be adjusted upwards by agreements between importers and exporters based on the amortised costs of exploration and drilling, trading and supply costs, transportation and distribution costs, and the application of country and political risk premia which are all unique in each bilateral trading arrangement. On the assumption that global supply of gas to terminals will immediately adjust to demand in a developed global marketplace, the fob export price benchmark ultimately might then depend on excess demand conditions.

Mazighi (2005) rightly suggests that, in the long-term and in accordance with economic theory, the evolution of prices

is guided by supply and demand. Price changes from period to period $\left(P_{t}-P_{t-1}\right)$ will adjust to excess demand $\left(E X_{t}\right)$. 


$$
P_{t}-P_{t-1}=\alpha+\beta E X_{t}+e_{t}
$$

If Beta is close to one and Alpha is close to zero it means that prices are driven by their fundamental values in the long-term.

However, Mazighi (2005) found that more than $80 \%$ of gas price changes in the US market were not driven by their fundamental values. In other words other factors need to be taken into account in a market not yet informationally efficient, to account for gas price changes. At the early stage of the development of the global market there are major market informational asymmetries that create a massive divergence between theory and reality.

Krichene (2005), in another attempt to engage economic theory, developed a simultaneous demand and supply equations model for world crude oil and natural gas markets, adopting the hypothesis of rational expectations given the role of market information in determining supply behaviour according to Muth (1961). Natural gas output in billions of cubic metres per year and the natural gas nominal price in US cents per cubic feet were adopted to represent supply and demand conditions.

The model confirmed low price and high income elasticities of demand for both oil and natural gas. However, the explanatory power of such a model would not be expected to be substantial given the absence of an integrated global market. More realistic models operating in a fragmented global natural gas market need to be specified if the ultimate aim is to explain an interim global benchmark price. Such a model would need to include not only the prices of major replacement fuels but also variables that contribute to the explanation of global supply and demand conditions. Together these variables, if selected from both theoretical and practical bases, should ideally capture most of the factors that affect supply and demand. On the bases that stock markets are proven economic indicators this paper examines the global stock market index as a proxy to partially reflect or provide an indication of supply and demand forces for natural gas.

\subsection{The relationship between oil, stock, coal and gas prices}

It reasonable in light of previous evidence that the relationship between gas prices and oil prices be continually tested. Though the evidence is mixed, much of it suggests growing integration of regional energy markets. Coal markets need to be included in any analysis as coal is a major replacement fuel. In the case of coal, there is evidence that the global markets are becoming more integrated and efficient. For example, Warell (2006) finds that both steaming and coking coal markets are showing signs of global market integration demonstrated in a stable long-term cointegrating relationship between price series in different world regions. Part of the determination of the price of gas must be related to the price of oil and coal as the most utilised alternative or substitute fuels. Studies such as, Pindyck (1999) and Serletis and Rangle-Ruiz (2004) have used cointegration tests to examine the relationship between oil, coal and gas, and oil and gas prices respectively in North American markets with mixed results in terms of the strength of the cointegrating relationships found.

Pindyck investigated 127 years of data in oil, coal and natural gas and questioned whether or not models of reversion to stochastically fluctuating trend lines can assist in the forecasting of prices over 20 year horizons. Serletis and Rangle-Ruiz, in an investigation of daily oil and gas data from 1991 to 2001 find that North American gas prices are largely defined by the Henry Hub $(\mathrm{HH})$ gas price. In addition there had been a decoupling of North American gas and crude oil prices over the period due to deregulation of these markets after an investigation of shared trends and prices using the $\mathrm{HH}$ and the West Texas Intermediate crude oil price. That is, the markets were integrated but the relationship was weakening.

Asche (2006) examined whether or not decoupling of natural gas prices from prices of other energy commodities (such as oil and electricity) had taken place in the liberalised UK and the regulated continental gas markets after the Interconnector had integrated these markets after 1998. Asche finds that monthly price data from 1995 to 1998 indicated a highly integrated market where wholesale demand appeared to be for energy generally.

A comprehensive study of the North Western European market was undertaken by Stern (2007) who questioned the rationale behind the continuing link of gas prices to oil product prices in continental European long-term gas contracts. The choice between burning oil and gas products during the 1970s and 1980s was determined in a robust way by price incentives, but the continuing strength of this rationale is doubtful today. Stern implies that that whilst there is a dominant influence of oil on gas prices in Europe, this will weaken as the scale and speed of competition increases.

Bachmeier (2006) finds, using daily price data for five different crude oils that the world oil market is a single highly integrated economic market. In addition he finds that the coal markets in the United States, while cointegrated, show a weaker degree of market integration. He also finds that crude oil, coal and natural gas markets in the United States are only weakly integrated. He concludes that there is not a primary energy market in the United States. 
Most researchers agree that the price of oil has something to do with the price of gas. Some also agree that other energy prices such as coal are related to oil and gas prices (For example, Bachmeier, 2006; Pindyck, 1999). If this is the case in North America as well as in Continental Europe, then an interim global gas pricing model remains possible, with oil and coal prices partial forecasters of gas prices. The rationale behind such a model would lie in its joint purpose as partial price forecasting model and an indicator model for party to party bargaining for replacement fuels.

The question is, in a global context, which proxies should be used. Evidence has been provided that OPEC oil prices drive other global oil prices, including those in the USA (Simpson, 2006). On this basis OPEC prices are a logical proxy for oil prices. The HH gas price is sourced from the largest, most developed and efficient USA market. It follows that the HH prices be used to proxy gas prices in any basic analytical model for replacement fuels. Coal markets appear to possess a degree of global integration and global indices (For example, the Global Insight Coal Price Index) for both steaming and coking coals are available (Warell, 2006). Whichever proxies are selected according to logical criteria, the caveat remains that the global oil market is not informationally efficient and the global gas market is not well developed. In the model in this paper stock prices in a global index are deemed to be a reasonable proxy for global supply and demand conditions that should in part spillover to global energy prices.

Oil is the primary replacement fuel. Mazighi (2005) noted that the NBP was significantly related to oil prices. There is also evidence of a statistically significant relationship between oil and gas prices and industrial stock prices. Mazighi (2005), in testing the long-term behaviour of the UK National Balancing Point (NBP) gas prices found a relationship between the changes in the volume of manufactured production using ordinary least squared (OLS) regression analysis. As oil is used as a source of industrial power it follows that there is a relationship between industrial stock prices as well as alternative energy prices.

An increased amount of gas consumption is for industrial power generation and that part of demand for gas there fore arises from the industrial sector. The share of natural gas as a global energy source has been on the increase since the mid 1970s (Okogu, 2002) and it will increase substantially over the next decade with new producers (such as, Australia) strongly developing their export capacity. With the present lack of openness of the global markets, can it be said that gas prices should be fully indexed to oil prices when global oil markets are also not efficient? This investigation goes further to combine a stock market indicator with price indicators of competing energy sources in oil and coal.

\subsection{A basic party to party bargaining model}

International gas pricing is usually undertaken through negotiations between buyers and sellers on a bilateral basis. Okogu (2002) refers to a complex interplay of factors that relate to the general conditions in a country, the quality of the product, market conditions and taxation environments as well as a global pricing basis according to supply and demand. The factors include whether or not a country is gas poor or gas rich, who is to share the risks, the reliability of the supplies and flexibility of delivery, the quality of the product and what the competing fuels are.

A party to party bargaining model is expanded for gas pricing by Okogu (2002). The model posits that one of the principles of gas pricing is to relate the price of gas to its value in the market for competing energy sources (For example, oil).

Relating the spot price of gas to the price of a competing fuel, as in Okogu (2002), produces the following model.

$$
P_{G_{t}}=\alpha+\beta P_{o_{t}}+e_{t}
$$

Where

$P_{G_{t}}$ Is the price of gas at time t.

$\alpha$ Is a base spot price of gas agreed at the outset.

$\beta$ Is the pass-through price coefficient negotiated under the contact.

$P_{o_{t}}$ Is the price of the competing fuel (for example, oil).

$e_{t}$ Is the residual term for the regression which represents an intertemporal gas price escalation coefficient where $e_{t}=0$ except in those periods where there have been price adjustments.

It is evident that the caveat on strong global gas market expansion will be whether or not FDI can be mobilised in a high development cost environment to release "stranded" resources. Natural gas reserves should substantially increase over the next decade. Even greater competition with oil as an energy source will result. Gas is regarded as a cleaner and less expensive energy source than oil or coal. It is found along-side oil in many producing countries. It follows that the relationship between gas prices and oil prices needs to be tested. This is because part of the determination of the price of gas must be related to the price of oil as the most utilised alternative or substitute fuel. However, coal is also a strong 
alternative energy source. The study in this paper also examines the impact of coal prices which is another major competing industrial power source.

\subsection{Is the HH an acceptable benchmark price series?}

It remains necessary to specify the endogenous variable in the benchmark/party to party bargaining model. If the specified variables in this study explain a significant proportion of the variance in the HH then it is put that the HH may be an acceptable and available interim gas pricing benchmark. The questions are as follows: Which is the most developed and deregulated market and thus the most likely global leader in global gas market integration? Which market is the greatest consumer of natural gas? Which market supplies itself to the greatest degree? Which market is showing the greatest transition from for example, coal and oil fired power generation for industry? Which market has an established benchmark for natural gas already? Is this benchmark directly related to demand conditions under conditions of immediately adjusted supplies and to other factors such as global stock prices, oil prices and economic expectations?

The price benchmark in the Americas is the Henry Hub (HH). This price is determined at a physical location in Louisiana USA and has a greater potential than the NBP price in UK as a candidate to become a global benchmark price for natural gas (Mazighi, 2005). This is because more gas in the UK market is sold on long-term contracts with prices indexed to oil. Even though the HH is said to show less normality in fluctuation than the NBP price, the USA is the largest market (estimated at more than 660 billion cubic metres compared to 100 cubic metres in the UK in 2007).

The HH prices are quoted on the New York Mercantile Exchange (NYMEX) on a daily basis. The HH price represents standardised quantity and quality of gas in terms of methane content percent, heat value per cubic metre, and carbon dioxide and other impurity content percent. Other requirements of a benchmark are probably more likely to be met by the HH rather than NBP. It is more likely that suppliers and consumers can meet or connect electronically and offer exchange of physical for physical product, futures against futures and futures against physical product swaps in the USA and the Americas.

The Americas market is more likely to be able to report continuous information with transparency and without discrimination or privileged access to that information. In addition, that market has a larger number of players so that the market is liquid. Supply can quicker adjust to demand without any need for discounting. It is more likely that the $\mathrm{HH}$ will be predictable in the short-term and converge to equilibrium with other gas prices in the long-term.

The issues in this study are as follows: Are world stock prices, oil and coal prices and the changes in these prices significantly related to $\mathrm{HH}$ gas prices and the changes in these prices? Are the specified explanatory variables demonstrated to be exogenous? If the answer to these questions is yes, it is posited that the pricing model could in future become a useful interim benchmark spot price or indicator spot price for natural gas, which may assist in party to party bargaining.

\section{The model and methodology}

It is quite clear that any interim model for preliminary analysis must assume that energy markets are integrated and efficient and that mechanisms for the arbitraging of the different energy markets are in place. It would assume that all energy users in industry can easily move between different methods and fuels for power generating. Despite the fact that most natural gas is sold on long-term contracts, it is a spot pricing model that is being proposed and therefore it is appropriate to study daily data. In light of the above the paper seeks a theoretical model for analysis, but one that may prove useful as an interim spot natural gas price benchmark in the absence of any alternative.

This paper examines daily natural gas prices in an optimally lagged VAR in order to run VAR based cointegration and causality tests. It extends exogeneity testing to run variance decomposition analysis. The exogenously treated price variables are for coal, oil and global stock market prices. It combines a basic econometric model using global stock price index values to control for economic factors and the competing energy prices of OPEC oil prices and coal prices in an expanded party to party bargaining model.

Even though the oil market is inefficient and dominated by the production allocation behaviour of the OPEC cartel, daily OPEC oil prices are selected as the proxy for oil prices on the basis of a study by Simpson (2006) which identified OPEC oil prices as the principal driver of world and US oil prices. There is no real choice here. The OPEC countries control the oil market.

Coal fired power generation is also a significant contributor to industrial energy as a replacement fuel and the prices of that power source need to be included in any party to party bargaining model. Initially a regression model is specified to investigate unlagged relationships between prices. Based on Equations 1) and 2) in the literature the following model is put forward.

$$
P_{G_{t}}=\alpha_{t}+\beta_{1}\left(P_{S_{t}}\right)+\beta_{2}\left(P_{O_{t}}\right)+\beta_{3}\left(P_{C_{t}}\right)+e_{t}
$$


Where:

$\alpha_{t}$ Is the base price of gas agreed to at the signing of the spot contract.

$P_{G_{t}}$ Is the daily spot gas price.

$P_{S_{t}}$ Is the daily stock market price.

$P_{O_{t}}$ Is the daily oil price.

$P_{C_{t}}$ Is the daily coal price.

$\beta_{1}, \beta_{2}$ and $\beta_{3}$ are the pass through price coefficients negotiated under the spot contract as applicable to world stock market price index value, global oil price and global coal price.

$e_{t}$ Is the regression residual which represents an intertemporal price coefficient not explained by stock, oil or coal prices and $e_{t}=0$ except in times of price adjustments.

The specified exogenous variables as stated above are daily world stock price index values, oil prices and the coal prices. It is proposed that increases in economic indicators such as oil, stocks and coal prices are leading signals to gas producers to increase their prices to maintain market share in a competitive industrial power producing market.

On the bases of the verification of prices as integrated non-stationary processes (with first differences (price changes) being proven as stationary) a VAR model is specified with gas prices as the endogenous variable. The VAR based cointegration tests (Johansen, 1988) and causality tests (Granger, 1988) are undertaken to confirm whether or not there are long-term equilibrium relationships on optimally lagged data and to confirm the gas price variable's endogeneity in the short-term. Variance decomposition analysis in prices and price changes is also used to confirm causality.

The model to be tested is the VAR. The specification of the VAR is as follows:

$$
P_{G_{t}}=a\left(P_{G_{t-1}}\right) \ldots a\left(P_{G_{t-n}}\right)+b\left(P_{S_{t}}\right)+c\left(P_{O_{t}}\right)+d\left(P_{C_{t}}\right)+e_{t}
$$

The above equation also implies that all other variables in stock, oil and coal price variables are lagged along with the gas price variable. As part of the preliminary analysis, non-stationarity of the data is tested using Augmented Dickey-Fuller (ADF) tests (Dickey \& Fuller, 1981) with MacKinnon critical values (Eviews, 2001). Durbin-Watson (Durbin \& Watson, 1971) tests are applied to test for serial correlation in the errors of the regressions. White tests are applied to test for heteroskedasticity in the errors of the regressions.

\section{Data}

Daily data are extracted for the period January $1^{\text {st }}, 2002$ to January $1^{\text {st }}, 2007$. This period includes a short period of steady prices to the end of 2003 and strong price increases thereafter for the majority of the sample period. Oil prices have risen strongly since the end of 2003 and this should be useful to highlight anticipated positive relationships between all variables.

The HH spot price is determined at the Louisiana central location in the USA. It represents a standardised quality of gas in methane content and a standardised quantity. The price is expressed in US dollars per billion cubic metres British Thermal Units (BTU). These prices are also quoted on the New York Metals Exchange (NYMEX) and on Datastream.

The spot OPEC oil price is an oil basket price for OPEC member production in US dollars per barrel. These data are obtainable from the United States Department of Energy, Energy Information Administration and are also published in and extracted from Datastream.

The world stock market price index values are reported by Datastream who base their series on stock exchange price indices that commonly use a representative sample of publicly listed companies in each country, with the stock prices reflected in the index converted into US Dollars at current exchange rates. The companies included in the index generally represent around $85 \%$ of the volumes traded in the country stock exchanges. The index is regularly re-assessed (at least every quarter) to identify changes in the trading volumes of each represented company share. Then a new portfolio is compiled, with new weightings based on the changes in trading activity in each share.

The companies represented in the index commonly represent around $70 \%$ of the total stock market capitalisation of listed companies in each market. The indices generally reflect information that has been updated daily for the morning following the reference day and may be regarded as an important global economic indicator, reflective in part of global supply and demand conditions (and therefore in part reflective of global supply and demand for manufactures requirements of energy). 
Coal prices represent the ARA global insight price index values at US dollars per metric ton and are published in the Datastream database. The quote region for the coal is Europe and the delivery condition applies for the markets in Amsterdam, Rotterdam and Antwerp. The index is of three coal prices applicable for Colombian, Australian and South African coal.

\section{Preliminary results}

Table 1 contains the results of the ADF unit root tests applied to level series (prices) and first differences (price changes). The first differences and the errors of the regression of first differences are shown to be stationary at the $1 \%$ significance level.

\section{Main findings}

The analysis moves now to an investigation of optimally lagged data in the application of the Equation 4 in order to apply VAR based tests of cointegration and causality. This is on the basis that the unit root tests indicate that the level series are integrated and non-stationary (See Table 1).

The VAR stability condition check indicates that no root lies outside the unit circle (See Table 2) and that the VAR is stable. Note that in all Tables that follow, PG, PO, PC and PS are level series prices for gas, oil, coal and stocks respectively (Price changes are denoted (DPG), D(PO), DPC) and D(PS) respectively).

The VAR lag order test results, contained in Table 3, indicate that the optimal lag is four days according to the Log Likelihood, Final Prediction Error, and Akaike Information Criteria and three days according to the Schwarz and Hannan-Quinn information criteria.

Whilst unit root tests indicate integrated non-stationary processes, the summarised Johansen cointegration tests (See Table 4) indicate that there are no cointegrating relations in the specified model, tested at a $5 \%$ level of significance.

Table 5 contains the results of the VAR based Granger causality tests on prices. Significance levels of $10 \%$ are selected.

When gas prices are treated endogenously as specified, the only statistically significant Granger causality runs from the oil price to the gas price variable (That is, oil price variable's exogeneity is significant at the $5 \%$ level) on a 3 to 4 day lag. When all variables are considered together, causality is significant at the $10 \%$ level. Within the same system, when oil prices are considered endogenously, causality runs from stock prices to oil prices and from coal prices to oil prices (both significant at the $10 \%$ level). In this latter model gas price exogeneity is not significant. However, when all variables are considered together, joint causality running to oil prices is significant at the $10 \%$ level.

Table 6 shows the results of pairwise Granger causality tests that confirm the VAR based test on an optimal lag of 2 days according to the significance and size of the F statistic.

Price changes are now considered. Table 12 shows that in an unlagged model of gas price changes regressed on oil price, coal price and stock price changes, the only statistically significant relationship is with oil price changes (at the $1 \%$ level of significance). Serial correlation according to DW statistics is not a problem, but the explanatory power of the model is not strong. Nevertheless, it is deemed that this constitutes sufficient evidence to pursue exogeneity issues for the lagged prices and price change models.

Table 7 shows that the lag order for price changes is three days according to the log likelihood ratio, the final prediction error and the Akaike information criterion and two days according to the Schwarz and Hannan-Quinn criteria.

Table 8 shows the results of the VAR based Granger causality tests in price changes.

The table confirms that the significant influence on gas price changes is the oil price change and that the significant influences on the oil price changes are the price changes of coal and stocks at the $1 \%$ and $5 \%$ levels of significance respectively. It is also significant that the price change variables considered collectively are significant causal influences (at the $1 \%$ level) of the oil price change variable.

Table 9 shows the results of pairwise Granger causality testing for price changes.

Table 9 confirms these relationships established from results in Table 8, when considered on a pairwise basis with a lag of 2 days, based on the size and significance of the F statistic (Oil prices changes Granger cause gas prices at a 5\% level of significance, and coal and stock prices changes Granger cause oil price changes at a $1 \%$ and $10 \%$ level of significance respectively).

However, further evidence was sought for dynamic relationships within the gas price changes model. Table 10 contains the results of variance decomposition analysis. The results confirm Granger causality analysis. Gas price changes are treated endogenously in a model interacting with stocks, oil and coal price changes. In variance decomposition, the responses by each of the exogenously treated variables may be observed after a one standard deviation shock is imparted to the endogenous variable. 
Table 10 shows that within two days of the shock, the gas price change variable explains $99.66 \%$ of its own variance and $99.24 \%$ of its own variance after equilibrium is achieved within 12 days. The oil price change variable is the greater exogenous force in the model explaining $0.28 \%$ of the variance of the gas price change variable within 2 days increasing to $0.50 \%$ of that variance when equilibrium is achieved. The exogeneity of the stock price index change variable increases from $0.002 \%$ after 2 days to $0.16 \%$ when equilibrium is achieved.

The coal price change variable increases its exogeneity from $0.08 \%$ to $0.09 \%$ over the same period. These results lend support to the oil price change being a significant determinant of the gas price change commencing after a 2 day lag.

Table 11 results show the variance decomposition of price changes when the oil price change variable is treated endogenously. When the oil price variable is shocked it explains $96.09 \%$ of its own variance after 2 days and its endogeneity reduces to $95.58 \%$ after equilibrium is achieved in 9 days. Over the same period the exogeneity of the gas price variable reduces very slightly but the exogeneity of the stocks price variable increases from $1.14 \%$ to $1.17 \%$ and that of the coal price variable increases from $0.38 \%$ to $0.77 \%$. The stocks and coal price variables increase exogeneity while the gas price variable slightly reduces its exogeneity.

Again supporting evidence is provided that the stock price and then the coal price variables are the major influences on the oil price variable in the respecified model. The gas price variable is not a causal influence on the oil price variable.

\section{Conclusion}

This study provides evidence of Granger causality in an expanded, optimally lagged, multivariate, party to party bargaining model for daily (spot) gas prices and price changes, when the gas prices are proxied by the spot HH gas price. The interacting variables include daily oil prices (proxied by OPEC prices), global stocks prices (proxied by global stock price index values) and global coal price index values (proxied by the ARA Global Insight Coal Index values).

The findings lend support to previous studies of causal relationships in Western energy markets. For example, in USA oil and gas by Serletis and Rangle-Ruiz (2004); in USA oil, gas and coal by Bachmeier (2006); in USA oil, gas and coal by Stern (2007); in global coal markets by Warell, 2006) and in the UK and Continental gas market by Asche (2006). The global gas market could in future, when markets become larger and more efficient, use these variables to assist in partially forecasting future spot gas prices, but also to assist in spot price bargaining in an expansion of the party to party bargaining model (For example, in support of Okogu, 2002).

A VAR based Granger causality test as well as pairwise Granger causality tests were undertaken on prices and price changes along with variance decomposition tests in price changes. In the short-term, the daily oil price and price change is the dominant exogenous force on gas prices and price changes on a lag of two to three days. Evidence is produced that within the specified model, coal price changes and then stock price changes are significant causal influences over oil price changes.

Literature (Simpson, 2006) suggests that cartel or strongly cooperating behaviour among OPEC producers is a significant driver of oil prices but, it is possible, in that pricing environment, that other pricing factors are also taken into account by OPEC members? It is possible that increased global stock market price changes represent a signal to the OPEC cartel that global industry can afford to pay more for oil generated industrial power and oil prices are increased accordingly.

It may also be that increased coal prices are also a signal to the OPEC cartel that oil prices need to be increased for the cartel to maintain its current leading market share of the global energy market. In other words, apart from arguments that relate to OPEC's cartel behaviour and market power, the economic indicators of the world stock market and the world coal market may be important determinants of OPEC pricing decisions, which in turn may be significant causal influences of the global gas market. Similarly, gas producers would want to at least maintain their market share of industrial power based on pricing in the oil market. It may be rational behaviour that prices in any energy market will adjust proportionally and positively to prices in other energy markets.

The USA gas market is by far the largest, most regionally integrated and efficient in the world. The $\mathrm{HH}$ is the benchmark for that regional spot gas market. The evidence lends support to the feasibility of the $\mathrm{HH}$ as an interim global gas pricing benchmark in the absence of an alternative model, because the specified exogenous variables represented by global price indicators, play a combined a role in the determination of the $\mathrm{HH}$ gas prices quoted (that is, with oil prices as the most important). The results show that oil and coal, as the most prolific of replacement energy sources for industrial power, may have a significant role to play in the future in spot gas pricing when the market becomes larger, more efficient and more integrated.

Future research in this area will be to improve the model by examining a volume weighted average of all regional gas spot prices. The new model will also examine the contribution of political risk to the combined spot gas price on the 
basis that international credit risk, specifically its political risk components, are likely to play a role in any commodity's export pricing. Assessing a country's willingness to pay would seem to be a fundamental factor in pricing.

\section{References}

Asche, F. (2000). European Market Integration for Gas? Volume Flexibility and Political Risk. CESifo Working Paper, Number 358, November.

Asche, F. (2006). The UK Market for Natural Gas, Oil and Electricity: Are the Prices Decoupled? The Energy Journal, Vol. 27, No. 2, 27-40.

Bachmeier, L J. (2006). Testing for Market Integration Crude Oil, Coal and Natural Gas. The Energy Journal, Vol. 27, No. 2, 55-72.

Brito, D L., and Hartley, P R. (2007). Expectations and the Evolving World Gas Market. The Energy Journal, Vol. 28, No. 1, 1-24.

Dickey, D. A., and Fuller, W. A. (1981). Likelihood Ratio Statistics for Autoregressive Time Series within a Unit Root. Econometrica, Vol. 49, 1022-1057.

Durbin, J., and Watson, G. S. (1971). Testing for Serial Correlation in Least Squares Regression-111. Biometrica, Vol. $58,1-42$.

Eng, G. (2006). A Formula for LNG Pricing. Ministry for Economic Development New Zealand. [Online] Available: http://www.med.govt.nz/Templates/multipageDocumentTOC 23939.aspx

EViews 4. (2001). EViews 4 User's Guide. Quantitative Micro Software, LLC.

Granger, C. W. J. (1988). Some Recent Developments in a Concept of Causality. Journal of Econometrics, Vol. 39, 199-211.

Johansen, S. (1988). Statistical Analysis of Cointegration Vectors. Journal of Economic Dynamics and Control, Vol. 12, 231-254.

Juris, A. (2005). The Development of Markets in the UK Gas Industry. Policy Research Working Paper, World Bank, Private Sector Department, Washington, DC.

Krichene, N. (2005). A Simultaneous Equations Model for World Crude Oil and Natural Gas Markets. IMF Working Paper Series, No. 32.

Mazighi, Ahmed El Hashemite. (2005). Henry Hub and National Balancing Point Prices: What Will be the International Gas Price Reference. Organisation of Petroleum Exporting Countries, Research Paper, September.

Muth, J F. (1961). Rational Expectations and the Theory of Price Movements. Econometrica, Vol. 29, pp. 315-335.

Okogu, B E. (2002). Issues in Global Natural Gas: A Primer and Analysis. IMF Working Paper, No. 40, February.

Pindyck, R. S. (1999). The Long-Run Evolution of Energy Prices. The Energy Journal, Vol. 20, No. 2, pp1-27.

Serletis, A., and Rangle-Ruiz, R. (2004). Testing for Common Features in North American Energy Markets. Energy Economics, Vol. 26, 401-414.

Simpson, J L. (2006). Oil Price Hikes: Blame Cartel Behaviour or Political Risk. Working Paper, Social Science Research Network.

Stern, J. (2007). Is There a Rationale for the Continuing Link to Oil Product Prices in Continental European Long-Term Gas Contracts?. Oxford Institute for Energy Studies, April, NG 19.

Warell, L. (2006). Market Integration in the International Coal Industry: A Cointegration Approach. The Energy Journal, Vol. 27, No. 1, 99-118.

\section{Notes}

Note 1. As prices are quoted Cost Insurance Freight (CIF) the regression lines might be closer together if prices were negotiated Free on Board (fob) leaving the importers to negotiate separately the transaction costs for insurance and freight.

Note 2. If lower political risk is taken into account (comparing New Zealand with for example China) it would, however be logical for New Zealand to negotiate lower political risk premia. 
Table 1. Unit Root Tests: ADF test statistics

\begin{tabular}{|l|l|l|}
\hline Variable & $\begin{array}{l}\text { Level series } \\
\text { (Daily price) }\end{array}$ & $\begin{array}{l}\text { First differenced series } \\
\text { (Daily changes in price) }\end{array}$ \\
\hline Gas & $-3.1001 * *$ & $-22.0914 *$ \\
\hline Stocks & $0.8893 * * *$ & $-29.1173 *$ \\
\hline Oil & $-1.2219 * * *$ & $-28.6330 *$ \\
\hline Coal & $-1.0716 * * *$ & $-36.1812 *$ \\
\hline Residual & $-3.3753 * *$ & $-22.2892 *$ \\
\hline
\end{tabular}

Note: * Significance levels are at $1 \%$. ** Significance levels are at $5 \% . * * *$ Not significant and the ADF test statistic critical values are as follows:

$\begin{array}{cc}1 \% \text { level } & -3.435165 \\ 5 \% \text { level } & -2.863554 \\ 10 \% \text { level } & -2.567892\end{array}$

Table 2. VAR stability condition check (prices)

Roots of Characteristic Polynomial

Endogenous variables: PG PO PC PS

Exogenous variables: $\mathrm{C}$

Lag specification: 12

\begin{tabular}{ll}
\hline \hline Root & Modulus \\
\hline \hline 0.999989 & 0.999989 \\
0.998273 & 0.998273 \\
0.988582 & 0.988582 \\
0.970825 & 0.970825 \\
$0.221232-0.047471 \mathrm{i}$ & 0.226267 \\
$0.221232+0.047471 \mathrm{i}$ & 0.226267 \\
0.007210 & 0.007210 \\
-0.003067 & 0.003067 \\
\hline \hline
\end{tabular}

No root lies outside the unit circle.

VAR satisfies the stability condition. 
Table 3. VAR lag order selection criteria (prices)

Endogenous variables: PG PO PC PS

Exogenous variables: $\mathrm{C}$

\begin{tabular}{ccccccc}
\hline \hline Lag & LogL & LR & FPE & AIC & SC & HQ \\
\hline \hline 0 & -20838.86 & NA & $1.07 \mathrm{e}+09$ & 32.14011 & 32.15605 & 32.14609 \\
1 & -7876.610 & 25824.57 & 2.282389 & 12.17673 & 12.25642 & 12.20663 \\
2 & -7805.604 & 141.0263 & 2.096781 & 12.09191 & 12.23535 & 12.14574 \\
$\mathbf{3}$ & -7732.802 & 144.1452 & 1.920940 & 12.00432 & $\mathbf{1 2 . 2 1 1 5 1 ^ { * }}$ & $\mathbf{1 2 . 0 8 2 0 7 ^ { * }}$ \\
$\mathbf{4}$ & $\mathbf{- 7 7 1 5 . 1 3 5}$ & $\mathbf{3 4 . 8 6 9 7 5 *}$ & $\mathbf{1 . 9 1 6 0 1 7 ^ { * }}$ & $\mathbf{1 2 . 0 0 1 7 5 ^ { * }}$ & 12.27269 & 12.10342 \\
5 & -7709.096 & 11.88376 & 1.945682 & 12.01711 & 12.35180 & 12.14270 \\
6 & -7705.264 & 7.515444 & 1.982551 & 12.03587 & 12.43432 & 12.18539 \\
7 & -7700.349 & 9.610780 & 2.016751 & 12.05297 & 12.51516 & 12.22640 \\
8 & -7695.370 & 9.704045 & 2.051348 & 12.06996 & 12.59591 & 12.26732 \\
\hline \hline
\end{tabular}

* indicates lag order selected by the criterion

LR: sequential modified LR test statistic (each test at 5\% level)

FPE: Final prediction error

AIC: Akaike information criterion

SC: Schwarz information criterion

HQ: Hannan-Quinn information criterion

Table 4. Johansen cointegration test summary (prices)

\begin{tabular}{|c|c|c|c|c|c|}
\hline \multicolumn{6}{|c|}{ Series: PG PO PC PS } \\
\hline \multicolumn{6}{|c|}{ Lags interval: 1 to 2} \\
\hline \multicolumn{6}{|c|}{ Selected $(0.05$} \\
\hline \multicolumn{6}{|c|}{ level*) Number } \\
\hline \multicolumn{6}{|l|}{ of } \\
\hline \multicolumn{6}{|c|}{ Cointegrating } \\
\hline \multicolumn{6}{|c|}{ Relations by } \\
\hline \multicolumn{6}{|l|}{ Model } \\
\hline Data Trend: & None & None & Linear & Linear & Quadratic \\
\hline \multirow[t]{2}{*}{ Test Type } & No Intercept & Intercept & Intercept & Intercept & Intercept \\
\hline & No Trend & No Trend & No Trend & Trend & Trend \\
\hline Trace & 0 & 0 & 0 & 0 & 0 \\
\hline \multicolumn{6}{|c|}{ Max-Eigenvalu } \\
\hline $\mathrm{e}$ & 0 & 0 & 0 & 0 & 0 \\
\hline
\end{tabular}


Criteria by

Rank and

Model

\begin{tabular}{cccccc}
\hline \hline Data Trend: & None & None & Linear & Linear & Quadratic \\
\hline Rank or & No Intercept & Intercept & Intercept & Intercept & Intercept \\
No. of CEs & No Trend & No Trend & No Trend & Trend & Trend \\
\hline \hline \multicolumn{7}{c}{ Log Likelihood } & & & & \\
& by Rank (rows) & & & & \\
& and Model & & & & \\
& (columns) & & & & \\
& -7772.269 & -7772.269 & -7768.523 & -7768.523 & -7766.037 \\
2 & -7766.651 & -7764.534 & -7761.393 & -7758.382 & -7756.533 \\
3 & -7761.677 & -7759.549 & -7756.822 & -7751.390 & -7749.810 \\
4 & -7758.707 & -7756.231 & -7755.340 & -7746.839 & -7746.612 \\
\hline \hline & -7758.190 & -7755.340 & -7755.340 & -7745.701 & -7745.701 \\
\hline
\end{tabular}

Akaike

Information

Criteria by Rank

(rows) and

Model

(columns)

\begin{tabular}{llllll}
0 & 11.98812 & 11.98812 & 11.98852 & 11.98852 & 11.99084 \\
1 & 11.99178 & 11.99007 & 11.98985 & $11.98676^{*}$ & 11.98853 \\
2 & 11.99643 & 11.99623 & 11.99512 & 11.98985 & 11.99049 \\
3 & 12.00416 & 12.00496 & 12.00513 & 11.99668 & 11.99787 \\
4 & 12.01565 & 12.01742 & 12.01742 & 12.00876 & 12.00876 \\
\hline
\end{tabular}

Schwarz

Criteria by Rank

(rows) and

Model

(columns)

$\begin{array}{llllll}0 & 12.11523^{*} & 12.11523^{*} & 12.13151 & 12.13151 & 12.14972 \\ 1 & 12.15067 & 12.15292 & 12.16462 & 12.16551 & 12.17919 \\ 2 & 12.18709 & 12.19484 & 12.20167 & 12.20434 & 12.21293 \\ 3 & 12.22660 & 12.23932 & 12.24346 & 12.24692 & 12.25208 \\ 4 & 12.26987 & 12.28752 & 12.28752 & 12.29475 & 12.29475\end{array}$


Table 5. Granger causality test (VAR based, in prices)

VAR Granger Causality/Block Exogeneity Wald Tests

Dependent variable: PG

\begin{tabular}{|c|c|c|c|}
\hline Excluded & Chi-sq & df & Prob. \\
\hline PO & 7.068890 & 2 & 0.0292 \\
\hline $\mathrm{PC}$ & 1.667972 & 2 & 0.4343 \\
\hline PS & 2.010098 & 2 & 0.3660 \\
\hline All & 11.47862 & 6 & 0.0747 \\
\hline \multicolumn{4}{|c|}{ Dependent variable: PO } \\
\hline Excluded & Chi-sq & $\mathrm{df}$ & Prob. \\
\hline PG & 0.311380 & 2 & 0.8558 \\
\hline PC & 4.978898 & 2 & 0.0830 \\
\hline PS & 5.725313 & 2 & 0.0571 \\
\hline All & 12.11456 & 6 & 0.0595 \\
\hline \multicolumn{4}{|c|}{ Dependent variable: PC } \\
\hline Excluded & Chi-sq & df & Prob. \\
\hline PG & 0.019562 & 2 & 0.9903 \\
\hline $\mathrm{PO}$ & 0.503505 & 2 & 0.7774 \\
\hline PS & 0.823582 & 2 & 0.6625 \\
\hline All & 0.994749 & 6 & 0.9858 \\
\hline \multicolumn{4}{|c|}{ Dependent variable: PS } \\
\hline Excluded & Chi-sq & df & Prob. \\
\hline PG & 1.104973 & 2 & 0.5755 \\
\hline PO & 3.754883 & 2 & 0.1530 \\
\hline $\mathrm{PC}$ & 4.004171 & 2 & 0.1351 \\
\hline All & 9.694740 & 6 & 0.1381 \\
\hline
\end{tabular}


Table 6. Pairwise Granger causality (Non-VAR based in prices)

Lags: 2

\begin{tabular}{|c|c|c|c|}
\hline Null Hypothesis: & Obs & F-Statistic & Probability \\
\hline PO does not Granger Cause PG & 1303 & 4.20437 & 0.01513 \\
\hline PG does not Granger Cause PO & & 0.17999 & 0.83530 \\
\hline PC does not Granger Cause PG & 1303 & 1.56082 & 0.21036 \\
\hline PG does not Granger Cause PC & & 0.07413 & 0.92856 \\
\hline PS does not Granger Cause PG & 1303 & 1.45179 & 0.23453 \\
\hline PG does not Granger Cause PS & & 1.10279 & 0.33226 \\
\hline PC does not Granger Cause PO & 1303 & 2.97429 & 0.05143 \\
\hline PO does not Granger Cause PC & & 0.05256 & 0.94880 \\
\hline PS does not Granger Cause PO & 1303 & 3.42900 & 0.03271 \\
\hline PO does not Granger Cause PS & & 2.15093 & 0.11679 \\
\hline PS does not Granger Cause PC & 1303 & 0.12424 & 0.88318 \\
\hline PC does not Granger Cause PS & & 1.97402 & 0.13931 \\
\hline
\end{tabular}

Table 7. Lag order selection criteria for price changes

VAR Lag Order Selection Criteria

Endogenous variables: $\mathrm{D}(\mathrm{PG}) \mathrm{D}(\mathrm{PO}) \mathrm{D}(\mathrm{PC}) \mathrm{D}(\mathrm{PS})$

Exogenous variables: $\mathrm{C}$

\begin{tabular}{ccccccc}
\hline \hline Lag & LogL & LR & FPE & AIC & SC & HQ \\
\hline \hline 0 & -7888.856 & NA & 2.290627 & 12.18033 & 12.19628 & 12.18632 \\
1 & -7817.823 & 141.5191 & 2.104120 & 12.09541 & 12.17514 & 12.12533 \\
$\mathbf{2}$ & -7741.426 & 151.7325 & 1.916869 & 12.00220 & $\mathbf{1 2 . 1 4 5 7 3 *}$ & $\mathbf{1 2 . 0 5 6 0 6 *}^{*}$ \\
$\mathbf{3}$ & -7724.809 & $\mathbf{3 2 . 9 0 0 6 8 *}$ & $\mathbf{1 . 9 1 5 0 4 8 *}$ & $\mathbf{1 2 . 0 0 1 2 5 *}$ & 12.20857 & 12.07905 \\
4 & -7718.200 & 13.04499 & 1.943010 & 12.01574 & 12.28685 & 12.11748 \\
5 & -7715.375 & 5.558732 & 1.982929 & 12.03607 & 12.37097 & 12.16175 \\
6 & -7710.327 & 9.901299 & 2.016743 & 12.05297 & 12.45166 & 12.20259 \\
7 & -7704.968 & 10.47837 & 2.050156 & 12.06939 & 12.53188 & 12.24295 \\
8 & -7698.897 & 11.83140 & 2.081843 & 12.08472 & 12.61099 & 12.28221 \\
\hline \hline
\end{tabular}

* indicates lag order selected by the criterion

LR: sequential modified LR test statistic (each test at 5\% level)

FPE: Final prediction error

AIC: Akaike information criterion

SC: Schwarz information criterion

HQ: Hannan-Quinn information criterion 
Table 8 . Granger causality in price changes (VAR based)

VAR Granger Causality/Block Exogeneity Wald Tests

Dependent variable: D(PG)

\begin{tabular}{cccc}
\hline \hline Excluded & Chi-sq & df & Prob. \\
\hline \hline D(PO) & $\mathbf{6 . 7 8 5 2 3 4}$ & $\mathbf{2}$ & $\mathbf{0 . 0 3 3 6}$ \\
D(PC) & 1.313697 & 2 & 0.5185 \\
D(PS) & 1.309473 & 2 & 0.5196 \\
\hline \hline & 10.06994 & 6 & 0.1217 \\
\hline \hline
\end{tabular}

Dependent variable: $\mathbf{D}(\mathbf{P O})$

\begin{tabular}{cccc}
\hline \hline Excluded & Chi-sq & df & Prob. \\
\hline \hline D(PG) & 0.370212 & 2 & 0.8310 \\
D(PC) & $\mathbf{1 3 . 5 5 6 7 6}$ & $\mathbf{2}$ & $\mathbf{0 . 0 0 1 1}$ \\
D(PS) & $\mathbf{6 . 6 4 5 9 1 3}$ & $\mathbf{2}$ & $\mathbf{0 . 0 3 6 0}$ \\
\hline \hline All & $\mathbf{1 9 . 1 0 7 1 3}$ & $\mathbf{6}$ & $\mathbf{0 . 0 0 4 0}$ \\
\hline \hline
\end{tabular}

Dependent variable: $\mathrm{D}(\mathrm{PC})$

\begin{tabular}{cccc}
\hline \hline Excluded & Chi-sq & df & Prob. \\
\hline \hline D(PG) & 1.746110 & 2 & 0.4177 \\
D(PO) & 1.587273 & 2 & 0.4522 \\
D(PS) & 0.600896 & 2 & 0.7405 \\
\hline \hline & & & \\
\hline \hline
\end{tabular}

Dependent variable: D(PS)

\begin{tabular}{cccc}
\hline \hline Excluded & Chi-sq & df & Prob. \\
\hline \hline D(PG) & 0.305059 & 2 & 0.8585 \\
D(PO) & 4.289463 & 2 & 0.1171 \\
D(PC) & 3.105275 & 2 & 0.2117 \\
\hline \hline & & & 0.2523 \\
\hline \hline
\end{tabular}


Table 9. Pairwise Granger causality tests (price changes)

Lags: 2

\begin{tabular}{|c|c|c|c|}
\hline Null Hypothesis: & Obs & F-Statistic & Probability \\
\hline D(PO) does not Granger Cause D(PG) & 1302 & 3.68391 & 0.02539 \\
\hline $\mathrm{D}(\mathrm{PG})$ does not Granger Cause $\mathrm{D}(\mathrm{PO})$ & & 0.12883 & 0.87914 \\
\hline $\mathrm{D}(\mathrm{PC})$ does not Granger Cause $\mathrm{D}(\mathrm{PG})$ & 1302 & 0.68270 & 0.50543 \\
\hline $\mathrm{D}(\mathrm{PG})$ does not Granger Cause D(PC) & & 0.66973 & 0.51202 \\
\hline $\mathrm{D}(\mathrm{PS})$ does not Granger Cause D(PG) & 1302 & 0.99034 & 0.37173 \\
\hline $\mathrm{D}(\mathrm{PG})$ does not Granger Cause D(PS) & & 0.39063 & 0.67671 \\
\hline $\mathrm{D}(\mathrm{PC})$ does not Granger Cause $\mathrm{D}(\mathrm{PO})$ & 1302 & 6.04455 & 0.00244 \\
\hline $\mathrm{D}(\mathrm{PO})$ does not Granger Cause $\mathrm{D}(\mathrm{PC})$ & & 0.55286 & 0.57544 \\
\hline D(PS) does not Granger Cause D(PO) & 1302 & 2.61544 & 0.07352 \\
\hline D(PO) does not Granger Cause D(PS) & & 2.19502 & 0.11177 \\
\hline $\mathrm{D}(\mathrm{PS})$ does not Granger Cause D(PC) & 1302 & 0.25901 & 0.77186 \\
\hline D(PC) does not Granger Cause D(PS) & & 1.36887 & 0.25476 \\
\hline
\end{tabular}

Table 10. Variance decomposition of gas price changes

\begin{tabular}{cccccc} 
Period & S.E. & $\mathbf{D}(\mathbf{G})$ & $\mathbf{D}(\mathbf{S})$ & $\mathbf{D}(\mathbf{O})$ & $\mathbf{D}(\mathbf{C})$ \\
\hline \hline 1 & 0.430590 & 100.0000 & 0.000000 & 0.000000 & 0.000000 \\
$\mathbf{2}$ & $\mathbf{0 . 4 3 1 3 2 9}$ & $\mathbf{9 9 . 6 5 7 5 1}$ & $\mathbf{0 . 0 0 1 8 5 3}$ & $\mathbf{0 . 2 5 8 7 7 5}$ & $\mathbf{0 . 0 8 1 8 6 2}$ \\
3 & 0.451032 & 99.30365 & 0.140158 & 0.470603 & 0.085594 \\
4 & 0.451075 & 99.28692 & 0.144074 & 0.477711 & 0.091298 \\
5 & 0.452895 & 99.24936 & 0.160526 & 0.499487 & 0.090628 \\
6 & 0.452900 & 99.24784 & 0.161322 & 0.499905 & 0.090930 \\
7 & 0.453072 & 99.24443 & 0.162731 & 0.501972 & 0.090870 \\
8 & 0.453073 & 99.24430 & 0.162801 & 0.502007 & 0.090896 \\
9 & 0.453089 & 99.24398 & 0.162935 & 0.502194 & 0.090890 \\
10 & 0.453089 & 99.24397 & 0.162941 & 0.502198 & 0.090892 \\
11 & 0.453090 & 99.24394 & 0.162953 & 0.502215 & 0.090892 \\
$\mathbf{1 2}$ & $\mathbf{0 . 4 5 3 0 9 0}$ & $\mathbf{9 9 . 2 4 3 9 4}$ & $\mathbf{0 . 1 6 2 9 5 4}$ & $\mathbf{0 . 5 0 2 2 1 6}$ & $\mathbf{0 . 0 9 0 8 9 2}$
\end{tabular}


Table 11. Variance decomposition of oil price changes

\begin{tabular}{cccccc} 
Period & S.E. & D(PG) & D(PS) & D(PO) & D(PC) \\
\hline \hline 1 & 0.610956 & 2.270968 & 0.731364 & 96.99767 & 0.000000 \\
$\mathbf{2}$ & $\mathbf{0 . 6 3 1 1 4 0}$ & $\mathbf{2 . 3 8 1 7 4 1}$ & $\mathbf{1 . 1 4 1 5 0 3}$ & $\mathbf{9 6 . 0 9 2 3 4}$ & $\mathbf{0 . 3 8 4 4 1 6}$ \\
3 & 0.632592 & 2.376743 & 1.224201 & 95.65584 & 0.743213 \\
4 & 0.632855 & 2.375428 & 1.263282 & 95.58638 & 0.774906 \\
5 & 0.632872 & 2.376771 & 1.266210 & 95.58123 & 0.775787 \\
6 & 0.632873 & 2.376763 & 1.266226 & 95.58123 & 0.775785 \\
7 & 0.632874 & 2.376909 & 1.266226 & 95.58108 & 0.775784 \\
8 & 0.632874 & 2.376910 & 1.266226 & 95.58108 & 0.775785 \\
$\mathbf{9}$ & $\mathbf{0 . 6 3 2 8 7 4}$ & $\mathbf{2 . 3 7 6 9 2 2}$ & $\mathbf{1 . 2 6 6 2 2 6}$ & $\mathbf{9 5 . 5 8 1 0 7}$ & $\mathbf{0 . 7 7 5 7 8 5}$
\end{tabular}

Table 12. The unlagged relationship between gas and oil price changes

Dependent Variable: D(PG)

Method: Least Squares

\begin{tabular}{cclcr}
\hline \hline Variable & Coefficient & Std. Error & t-Statistic & Prob. \\
\hline \hline D(PO) & $\mathbf{0 . 1 0 6 5 9 5}$ & $\mathbf{0 . 0 1 9 6 9 2}$ & $\mathbf{5 . 4 1 3 1 7 8}$ & $\mathbf{0 . 0 0 0 0}$ \\
D(PC) & -0.009414 & 0.015702 & -0.599551 & 0.5489 \\
D(PS) & $4.82 \mathrm{E}-06$ & 0.001829 & 0.002634 & 0.9979 \\
\hline \hline R-squared & 0.022326 & Mean dependent var & 0.002113 \\
Adjusted R-squared & 0.020824 & S.D. dependent var & 0.451381 \\
S.E. of regression & 0.446657 & Akaike info criterion & 1.228246 \\
Sum squared resid & 259.5526 & Schwarz criterion & 1.240148 \\
Log likelihood & -797.8164 & Durbin-Watson stat & $\mathbf{2 . 0 1 4 4 8 5}$
\end{tabular}

Note: D (PG) denotes gas price changes, D (PO) denotes oil price changes, and D (PC) and D (PS) denote coal and stock price index changes. 


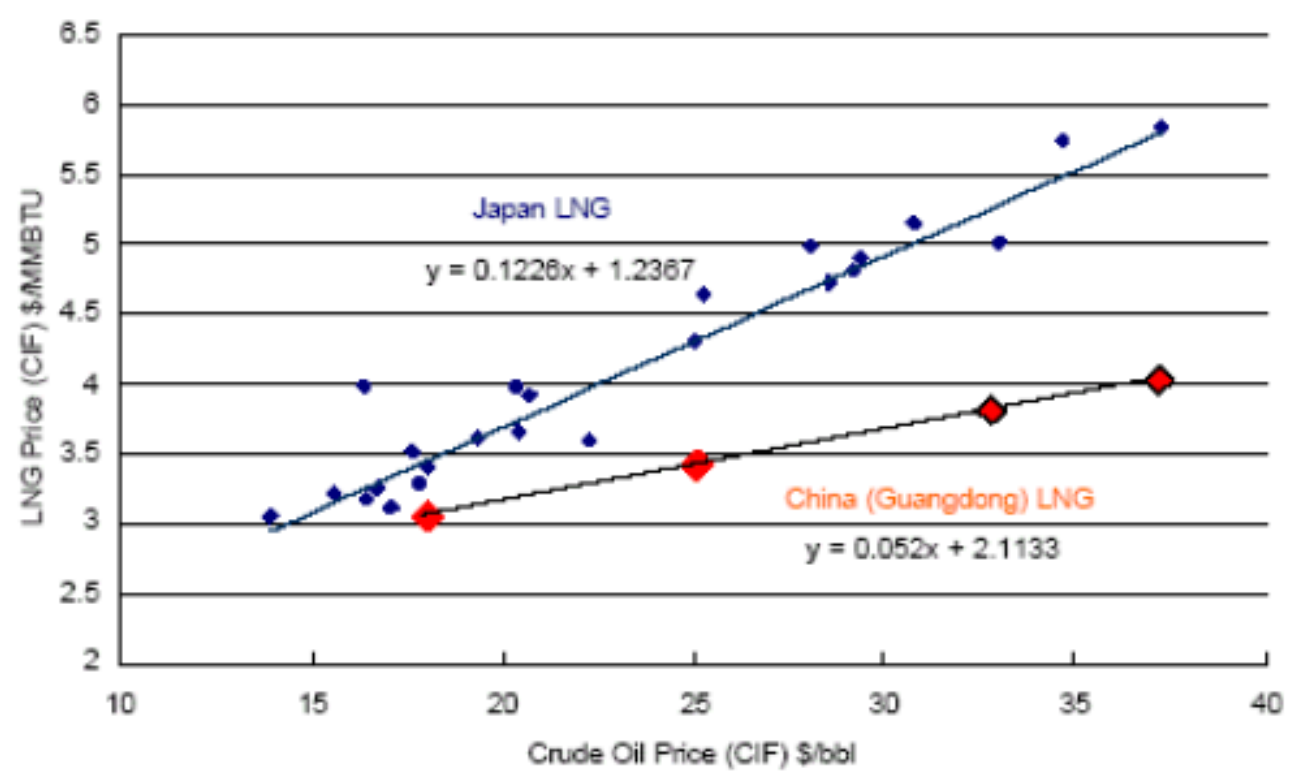

Figure 1. LNG Pricing Formulae - fitted

Source: Asia-Pacific Energy Research Centre, 2005. China data estimated by PetroStrategies; Japan LNG prices from IEA Energy Prices and Taxes, JCC prices from EDMC, Institute of Energy Economics of Japan. (Cited and produced in Eng, 2006).

Note: The equations in the above graph are estimates as stated where $\mathrm{y}$ is the gas price and $\mathrm{x}$ is the JCC oil price. Note the lower value of the Chinese coefficient for oil. The acronym BTU denotes a measure of gas quality in British Thermal Units. 